\title{
Development and Validation of Gas Chromatography-Triple Quadrupole Mass Spectrometric Method for Quantitative Determination of Regulated Plasticizers in Medical Infusion Sets
}

\author{
So Hyeon Jeon, ${ }^{1,2}$ Yong Pyo Kim, ${ }^{3}$ Younglim Kho, ${ }^{4}$ Jeoung Hwa Shin, ${ }^{5}$ Won Hyun Ji, ${ }^{6}$ \\ and Yun Gyong Ahn $\mathbb{1}^{1}$ \\ ${ }^{1}$ Western Seoul Center, Korea Basic Science Institute, Seoul 03759, Republic of Korea \\ ${ }^{2}$ Department of Environmental Science and Engineering, Ewha Womans University, Seoul 03759, Republic of Korea \\ ${ }^{3}$ Department of Chemical Engineering and Material Science, Ewha Womans University, Seoul 03760, Republic of Korea \\ ${ }^{4}$ Department of Health, Environment \& Safety, Eulji University, Seongnam 13135, Republic of Korea \\ ${ }^{5}$ Seoul Center, Korea Basic Science Institute, Seoul 02841, Republic of Korea \\ ${ }^{6}$ Institute of Mine Reclamation Technology, Mine Reclamation Corporation, Wonju 26464, Republic of Korea \\ Correspondence should be addressed to Yun Gyong Ahn; ygahn@kbsi.re.kr
}

Received 31 August 2017; Revised 26 November 2017; Accepted 7 December 2017; Published 5 February 2018

Academic Editor: Paolo Montuori

Copyright (C) 2018 So Hyeon Jeon et al. This is an open access article distributed under the Creative Commons Attribution License, which permits unrestricted use, distribution, and reproduction in any medium, provided the original work is properly cited.

\begin{abstract}
A method for the quantitative determination of dibutyl phthalate (DBP), benzyl butyl phthalate (BBP), bis(2-ethylhexyl) adipate (DEHA), bis(2-ethylhexyl) phthalate (DEHP), di-n-octyl phthalate (DNOP), dioctyl terephthalate (DOTP), diisononyl phthalate (DINP), and diisodecyl phthalate (DIDP) in medical infusion sets was developed and validated using gas chromatography coupled with triple quadrupole mass spectrometry (GC-MS/MS) in the multiple reaction monitoring (MRM) mode. Solvent extraction with polymer dissolution for sample preparation was employed prior to GC-MS/MS analysis. Average recoveries of the eight target analytes are typically in the range of $91.8-122 \%$ with the relative standard deviations of $1.8-17.8 \%$. The limits of quantification (LOQs) of the analytical method were in the ranges of 54.1 to $76.3 \mathrm{ng} / \mathrm{g}$. Analysis using GC-MS/MS provided reliable performance, as well as higher sensitivity and selectivity than GC-MS analysis, especially for the presence of minority plasticizers at different concentrations.
\end{abstract}

\section{Introduction}

Phthalates as a class of synthetic chemicals are widely used in a variety of consumer products including medical devices, toys for children, food wrapper, building materials, automotive parts, and so on [1-3]. Since they may cause harm to human health by altering endocrine function or through other biological mechanisms [4], environmental monitoring of phthalates has been accomplished from various media (air, soil, food, water, etc.) [5-9]. Most medical devices are made of flexible polyvinylchloride (PVC), a produced synthetic plastic polymer due to its numerous benefits, which include chemical stability, biocompatibility, clarity and transparency, flexibility, durability, chemical and mechanical resistance, sterilizability, and low cost [10].
Since plastics are mainly used as plasticizers to soften PVC, phthalates are abundant in PVC-based medical devices, and they may enter into contact with the patients through leaching out into infused solutions [11, 12]. The larger molecular weight phthalates-di(2-ethylhexyl) phthalate (DEHP), di-n-butyl phthalate (DBP), and diisononyl phthalate (DINP) - are suspected carcinogens, toxic to liver, kidneys [13], and reproductive organs [14]. Benzyl butyl phthalate (BBP), DBP, and DEHP are weakly estrogenic [15]. There have been reports of extraction of phthalates such as BBP, DBP, and DEHP in dialysis tubing and infusion bags $[16,17]$. Consequently, the European Chemicals Agency (ECHA) recommended that several compounds of very high concern should not be used without specific authorization. Furthermore, according to South Korea Ministry of Food 
TABLE 1: Summary of chemical information and instrument conditions of target analytes.

\begin{tabular}{|c|c|c|c|c|c|c|c|c|}
\hline Compounds & Abbreviation & $\begin{array}{c}\text { CAS } \\
\text { number }\end{array}$ & Formula & $\begin{array}{l}\text { M.W. } \\
\text { (g/mol) }\end{array}$ & $\begin{array}{l}\text { R.T. } \\
(\mathrm{min})\end{array}$ & Precursor ion & Product ion & $\begin{array}{l}\text { Collision } \\
\text { energy }(\mathrm{eV})\end{array}$ \\
\hline Dibutyl phthalate & DBP & $84-74-2$ & $\mathrm{C}_{16} \mathrm{H}_{22} \mathrm{O}_{4}$ & 278.35 & 10.126 & 149 & 121 & 12 \\
\hline Benzyl butyl phthalate & $\mathrm{BBP}$ & $85-68-7$ & $\mathrm{C}_{19} \mathrm{H}_{20} \mathrm{O}_{4}$ & 312.37 & 13.734 & 149 & 121 & 11 \\
\hline Bis(2-ethylhexyl) adipate & DEHA & $103-23-1$ & $\mathrm{C}_{22} \mathrm{H}_{42} \mathrm{O}_{4}$ & 370.57 & 14.032 & 129 & 101 & 2 \\
\hline Bis(2-ethylhexyl) phthalate & DEHP & $117-81-7$ & $\mathrm{C}_{24} \mathrm{H}_{38} \mathrm{O}_{4}$ & 390.56 & 15.251 & 149 & 121 & 13 \\
\hline Di-n-octyl phthalate & DNOP & $117-84-0$ & $\mathrm{C}_{24} \mathrm{H}_{38} \mathrm{O}_{4}$ & 390.56 & 16.642 & 279 & 149 & 3 \\
\hline Dioctyl terephthalate & DOTP & $6422-86-2$ & $\mathrm{C}_{24} \mathrm{H}_{38} \mathrm{O}_{4}$ & 390.56 & 16.716 & 261 & 149 & 8 \\
\hline Diisononyl phthalate & DINP & $20548-62-3$ & $\mathrm{C}_{26} \mathrm{H}_{42} \mathrm{O}_{4}$ & 418.61 & 17.482 & 293 & 149 & 3 \\
\hline Diisodecyl phthalate & DIDP & $26761-40-0$ & $\mathrm{C}_{28} \mathrm{H}_{46} \mathrm{O}_{4}$ & 446.67 & 18.877 & 307 & 149 & 4 \\
\hline
\end{tabular}

and Drug Safety (MFDS) regulation, phthalates within intravascular administration products including DEHP, DBP, and $\mathrm{BBP}$ are no longer being used in the production of medical infusion sets since July 2015.

Due to the expanding use of phthalates and assimilated analytes in medical devices, the analytical methods for plasticizers from infusion sets are increasing in order to create plans for safety. Several analytical methods capable of detecting and quantifying the alternative plasticizers in medical devices have been developed and validated by means of separative and nonseparative methods up to date [18]. The separative methods have been adopted with gas chromatography, supercritical fluid chromatography [19], and liquid chromatography combined with various detectors such as mass spectrometer, flame ionization detector, evaporative light scattering detector, or UV techniques. Nonseparative methods have been performed on a nuclear magnetic resonance and Fourier transform infrared spectrometry $[20,21]$. Among these methods, gas chromatography coupled with mass spectrometry was the most specific and sensitive method and suggested to be a suitable method to perform a regulatory control. Furthermore, application of GC-triple quadrupole mass spectrometry (GC-MS/MS) is recently increasing in terms of quantitative confirmation in various matrices [22].

For the sample preparation, an easy and inexpensive technique is polymer dissolution which is well known as a solid-liquid extraction [23]. The whole polymer is first dissolved in a solvent-like tetrahydrofuran (THF) or dimethylacetamide [24, 25]. After then, when solvent is added to the dissolution for solvent extraction, PVC-based polymers are removed by precipitation. There are already two publications by Gimeno et al. and Bourdeaux et al. dealing with the GC-MS analysis of phthalates and assimilated analytes in medical devices $[26,27]$. But the viewpoint of the detection level and target analytes is clearly different from our study. It is important to monitor the presence of the minority plasticizers, as well as the majority, because their migration and toxic potential can be extremely different depending on their chemical properties. Furthermore, alternative plasticizers and mixtures have been increasingly developed to provide flexibility for medical devices in these days. Also, their concentration levels in the samples can be quite varied, but they should be evaluated depending on the type of phthalates and assimilated analytes. Accordingly, the identification and quantification of toxic plasticizers in medical devices, especially the tubings of medical infusion sets, are needed since they are able to leach from infusion sets and result in human exposure directly.

The aim of this study was to evaluate the capabilities of GC-MS/MS for the quantification of phthalates and assimilated analytes from infusion sets. Analysis using GC-MS with a single quadrupole mass analyzer has been typically used in most cases for the determination of phthalates and assimilated analytes in medical devices. However, this method requires a clean matrix to avoid the interference of unwanted ions [28]. By conducting interlaboratory collaborative studies, it was found that there was a lack of accuracy and precision for quantitative GC/MS analysis due to insufficient cleanup procedures. The advantages of the proposed method rely also on the fact that there is no need for complete chromatographic separation due to the MRM mode. As for the sample preparation according to polymer dissolution, GC-MS/MS provides sensitive, efficient, and reliable results. This method would be a useful tool to control the safety of intravascular administration set and assess unintended harmful substances, especially for the presence of both majority and minority plasticizers at the level of various concentrations.

\section{Materials and Methods}

2.1. Chemicals and Reagents. Standard solutions of eight analytes (BBP, DBP, DEHA, DEHP, DNOP, DOTP, DINP, and DIDP; see Table 1 for their full chemical names and information) for GC-MS/MS analysis were purchased from Sigma-Aldrich (St. Louis, MO, USA), and stock solution was at a concentration of $2000 \mathrm{mg} / \mathrm{L}$ in hexane. Internal standards of benzyl benzoate (BB) were purchased from SigmaAldrich (St. Louis, MO, USA) and used at a concentration of $100 \mathrm{mg} / \mathrm{L}$ in hexane as a stock solution. Organic solvents (hexane and THF) of the GC analysis grade were purchased from Burdick \& Jackson (Philipsburg, NJ, USA).

2.2. Preparation of Samples. $50 \mathrm{mg}$ of small pieces from the tubings in medical infusion sets in $5 \mathrm{~mL}$ of THF was sonicated at room temperature for $30 \mathrm{~min}$ in a glass tube. Subsequently, $10 \mathrm{~mL}$ of hexane was added into the glass tube, and the solution was vortexed for the precipitating polymer matrix. After precipitating the polymer matrix, the solution was left as 


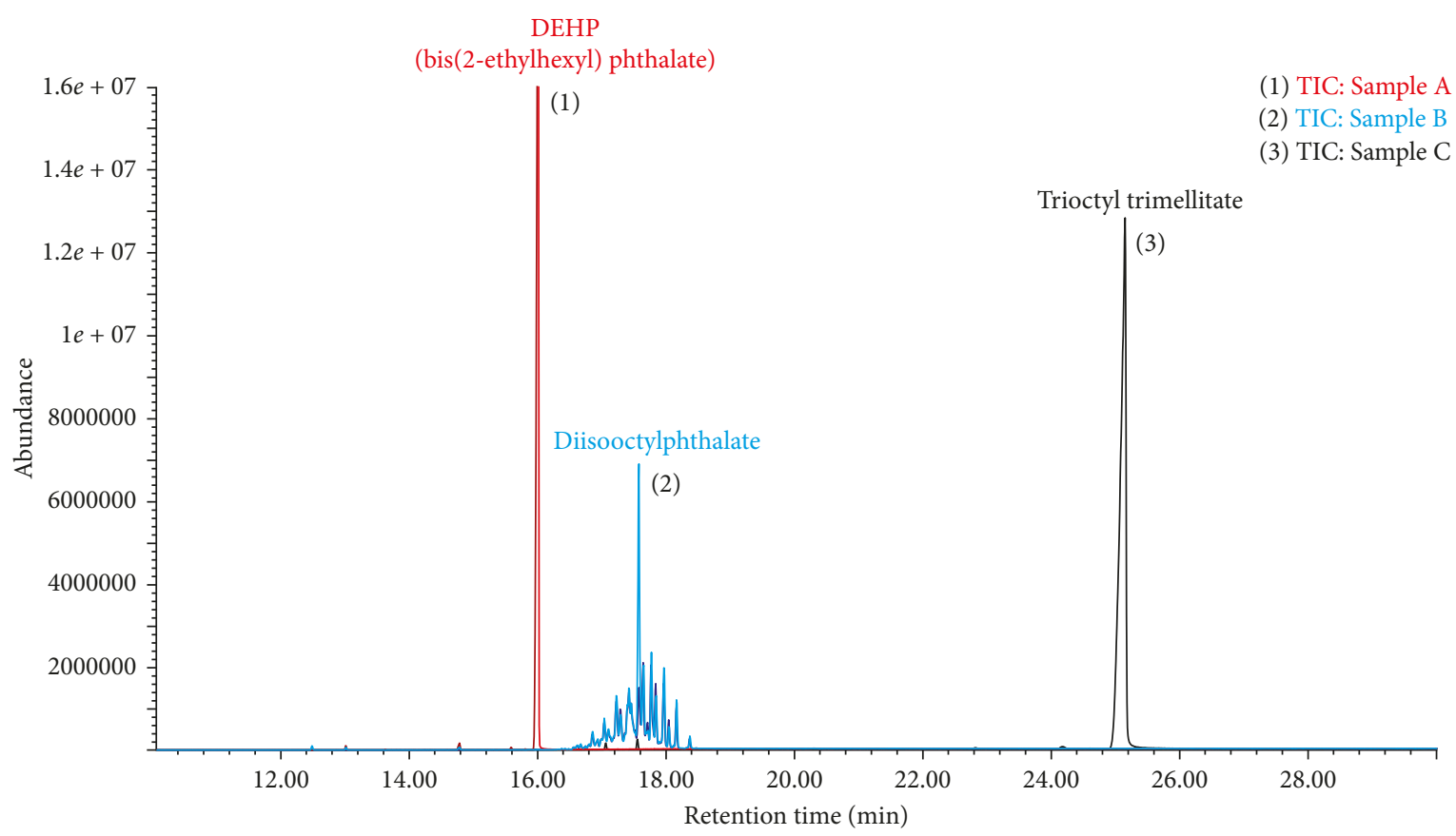

Figure 1: Total ion chromatograms of the hexane extracts after polymer dissolution in tubings of three domestic medical infusion sets. In the TICs, majority plasticizers for each sample are represented in a chromatogram with the three main peaks, each identified by different colors.

it was for $10 \mathrm{~min} .0 .5 \mathrm{~mL}$ of supernatant extracted samples was transferred into a $2 \mathrm{~mL}$ of vial while $100 \mathrm{ng}$ of internal standard was added. A total volume of $1 \mathrm{~mL}$ was homogenized and filtered by an Acrodisc $0.2 \mu \mathrm{m}$ GHP syringe filter.

2.3. Analysis Using GC-MS/MS. Analysis was performed by an Agilent 7890B gas chromatograph, equipped with a 7010 mass selective detector triple quadrupole mass spectrometer system (Palo Alto, CA, USA). Chromatographic separation was achieved using a DB-5MS UI (5\% diphenyl-95\% dimethyl siloxane phase, $30 \mathrm{~m} \times 0.25 \mathrm{~mm} \mathrm{I}$. D; $0.25 \mu \mathrm{m}$ film thickness) from a J\&W Scientific (Santa Clara, CA, USA) capillary column. The temperature of injector was $300^{\circ} \mathrm{C}$. One microliter of each extract was injected in the split mode (2: 1). Helium as carrier gas (99.999\%) flow was $1 \mathrm{~mL} / \mathrm{min}$. The GC oven temperature program was as follows. The initial temperature of $150^{\circ} \mathrm{C}$ was held for $3 \mathrm{~min}$ after injection before it was increased up to $300^{\circ} \mathrm{C}$ at $10^{\circ} \mathrm{C} / \mathrm{min}$ held for $12 \mathrm{~min}$. Nitrogen (99.999\%) was used as collision gas. The running time was $30 \mathrm{~min}$, divided into seven segments of time for each selected product ion to increase sensitivity and selectivity. The transfer line and ion source temperature were set at 250 and $230^{\circ} \mathrm{C}$, respectively. The mass spectrometer is tuned on electron impact ionization (EI) at $70 \mathrm{eV}$ in the multiple reaction monitoring (MRM) mode.

\section{Results and Discussion}

3.1. Sample Preparation. Previous studies and conventional extraction techniques, including Soxhlet, solvent extraction, or a method that firstly dissolves the whole polymer and then separates the plasticizers from the PVC by precipitation, are suggested. Due to the large volume of solvent needed and the long procedure times, solvent extraction after the polymer dissolution at room temperature has been used as an alternative efficient and simple technique instead of Soxhlet extraction [10]. In this study, $50 \mathrm{mg}$ of the cutting infusion tube was dissolved in $5 \mathrm{~mL}$ of THF and sonicated for $30 \mathrm{~min}$. The mixed solution was left for 10 min or more, and then the polymer was precipitated due to difference in polarity between THF and hexane. According to the solvent used for the phthalate extraction, an organic solvent such as dichloromethane [29] or acetone [30], hexane, and acetonitrile [31] has been used. The selection of different solvents for extraction can have significant effects on the discrimination of target analytes from the sample matrix, as well as the extraction recoveries [32]. Although the advantage of this sample preparation is simple without purification, the matrix effect based on the different organic plastic additives in infusion sets can lead to false results of target analytes [33]. As an extraction solvent after the polymer dissolution, hexane was chosen because the partitioning of the extract with hexane was able to minimize matrix interferences compared with other solvents. Figure 1 shows the total ion chromatograms of the hexane extracts after polymer dissolution in three domestic infusion sets using a GC-MS system. Sample A clearly showed a large amount of DEHP released from the sample suspected to be the PVC sets. Although the use of DEHP in medical tubing has been restricted, it is still used in medical devices within the medical industrial field. In the case of samples B and C, diisooctylphthalate (DIOP) and trioctyl trimellitate (TOTM) were mainly detected, respectively. These chemicals could be 
used as alternatives to regulated analytes in domestic medical devices, with their unwanted ions interfering with the detection of the target analytes. For spiking experiments, polyurethane (PU) sample containing none of the eight target analytes was used to evaluate the suitability of the analytical method.

3.2. GC-MS Analysis. A gas chromatography coupled with single quadrupole mass spectrometer with selected ion monitoring (SIM) mode has been frequently used to evaluate the analytical performance and validation for quantitative analysis in the clinical research field owing to high sensitivity and the ability to achieve low limits of detection [34]. Based on the test method of the standard operating procedure for the determination of phthalates in PVC products by the U.S. Consumer Product Safety Commission's (CPSC) testing laboratory (LSC) [35], three laboratories were involved in an interlaboratory collaborative study to test the practicability of the modified CPSC method for the quantitative determination of phthalates and assimilated analytes in infusion tubing samples. Accuracy, precision, and linearity as evaluation parameters between laboratories were performed using the sample preparation procedures (Section 2.2) with the same type of commercial GC-MS instrument. All the investigated calibration curves were obtained by the acceptable correlation coefficients $\left(R^{2}>0.99\right)$ at five concentrations ranging from 0.05 to $5 \mu \mathrm{g} / \mathrm{g}$ for DBP, BBP, DEHA, DEHP, DNOP, and DOTP and from 0.15 to $15 \mu \mathrm{g} / \mathrm{g}$ for DINP and DIDP, respectively. However, it was found that there was a lack of accuracy and precision from the results of the spike recovery comparison of collaborative studies. The accuracy and precision were assessed by recovery experiments between laboratories using triplicate target analyte free samples spiked with three different concentration points (low, middle, and high) in the calibration range compared with the pure authentic standards. Over $60 \%$ of the 144 individual results reported fell outside of the acceptable limits for recoveries (normally ranging from 70 to $130 \%$ ) and precision $(<20 \%$ RSD). These results indicated that the analytical method of extraction solvent after the polymer dissolution in the medical infusion sets followed by GC-MS was unsuitable for the determination of trace level concentration of phthalates and assimilated analytes. As mentioned by the U.S. Consumer Product Safety Commission (CPSC), it was intended to address the determination of concentrations of more than 0.1 percentage per plasticized component part of toys for children or child care article in order to protect children from hazard [35]. Therefore, triple quad GC-MS system allows the simplification of sample preparation while maintaining high selectivity and sensitivity when targeting trace level of analytes in complex sample extracts [36].

3.3. Optimization of the GC-MS/MS Conditions. For GCMS/MS analysis using the triple quadrupole, full-scan spectra were obtained to select the precursor ions of each target analyte. Figure 2 shows the full-scan MS/MS data of each analyte to optimized MRM transitions. A mass-tocharge ratio of 149 or 129 was selected as precursor ions of DBP, BBP, DEHA, and DEHP due to their highest mass intensity. Mass-to-charge ratios of 279, 261, 293, and 307 were selected as precursor ions of DNOP, DOTP, DINP, and DIDP generally considered as confirmation ions for increasing selectivity. Collision-induced dissociation (CID) for selected precursor ions using $99.999 \%$ nitrogen was acquired to find the appropriate collision energy of each analyte. To determine collision energies (CEs) for both the quantifying and qualifying MRM ion transitions, they were varied between 2 and $20 \mathrm{eV}$ and optimized as shown in Table 1. This shows that the precursor ions and dominant fragmented ions of phthalates in EI ionization were typically $\mathrm{m} / \mathrm{z} 149$, corresponding to the protonated phthalic anhydride ion $\left[\mathrm{C}_{8} \mathrm{H}_{5} \mathrm{O}_{3}\right]^{+}$[37]. The useful dissociation pathway for phthalates was provided by the relatively low collision energy of the molecular ion. Figure 3 shows the mass spectral fragmentation pathway of DINP in the MRM mode as an example. The molecular ion loses the alkyl fragment accompanied by two hydrogen migrations. Since the molecular ion peak for phthalates with long chain alkyl groups is usually weak, it was not always present in the mass spectra. But the ions loosing alkyl group $[\mathrm{M}-\mathrm{R}]^{+}$and those with oxygen $[\mathrm{M}-\mathrm{OR}]^{+}$fragments can be a secondary form of identification [38]. In the MRM mode, $\mathrm{m} / \mathrm{z} 293$ cleaved again to $\mathrm{m} / \mathrm{z} 149$, losing the remaining alkyl fragment as shown in Figure 3. The main product ion from $\mathrm{m} / \mathrm{z} 149$ is $\mathrm{m} / \mathrm{z} 121$, resulting from fragmentation with loss of the aldehyde group. A similar fragmentation pattern was observed in the other analytes except different alternative plasticizers such as bis(2-ethylhexyl) adipate as shown in Figure 2.

To verify the presence of target analytes in matrix blank samples, $5 \mu \mathrm{g} / \mathrm{g}$ (the concentration of solid by weight) was spiked in the matrix sample and the same experimental process was conducted. The spiked and matrix blank sample were analyzed by the same instrument condition. Figure 4 shows MRM chromatograms of matrix blank sample (a) and those spiked with target analytes $(5 \mu \mathrm{g} / \mathrm{g})$ (b). As a result, target analytes were not observed in the matrix blank sample, and each peak of target analytes were separated clearly in the MRM mode.

3.4. Analytical Performance. Method validation was performed by spike recovery experiments based on the optimized analytical methods. In this study, benzyl benzoate was used as an internal standard (IS) for target analytes. The calibration curves were generated in the range of $5-500 \mathrm{ng} / \mathrm{g}$ using a least-square linear regression analysis. The correlation coefficients were all greater than 0.999 compared with results obtained by GC-MS. The limit of quantification (LOQ) for each analyte was determined in accordance with ICH guidelines [39]. The calculated LOQs ranged from 54.1 to $76.3 \mathrm{ng} / \mathrm{g}$, and they were approximately 20 times lower compared with the results from the latest study which was performed to determine LOQ by the GC/MS method [18]. To validate the accuracy and precision of the analytical method, three replicate analyses of matrix blank samples spiked with the known amounts of the analytes at low and middle concentration levels (17 and $100 \mathrm{ng} / \mathrm{g}$ ) were prepared 

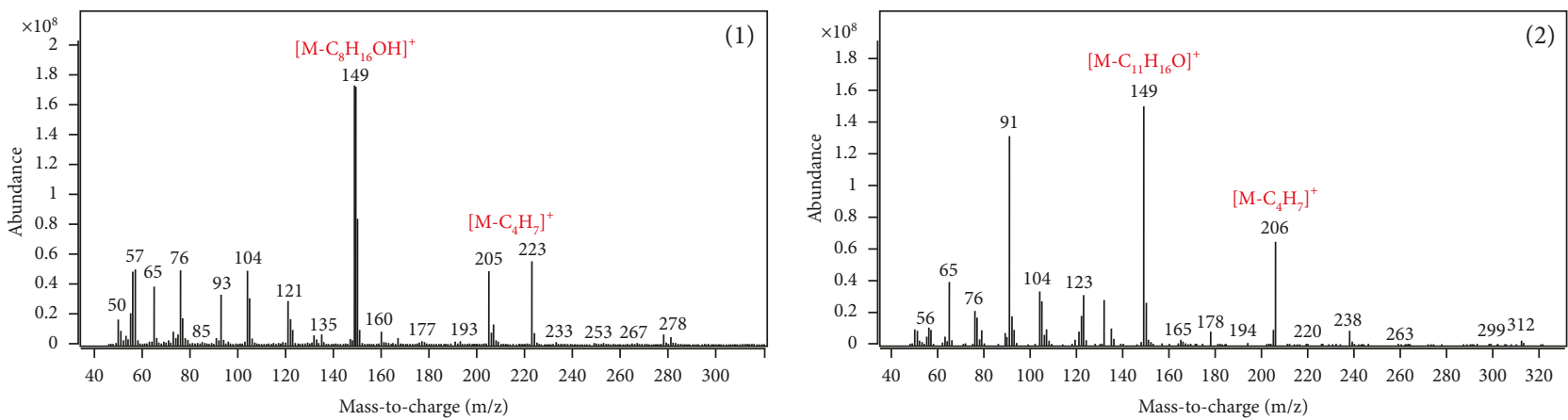

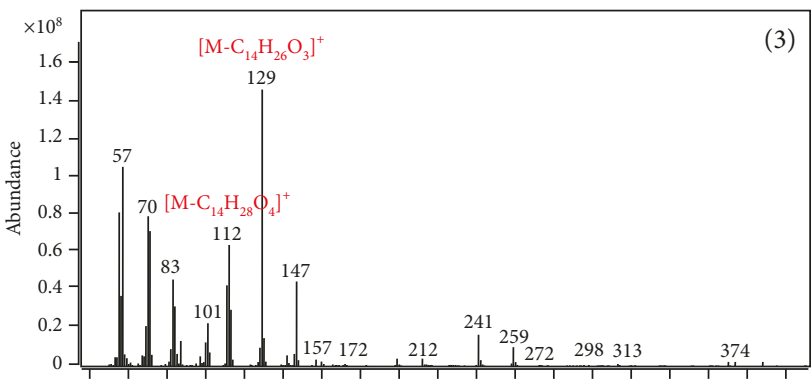

$60 \quad 80100120140160180200220240260280300320340360380400$ Mass-to-charge $(\mathrm{m} / \mathrm{z})$
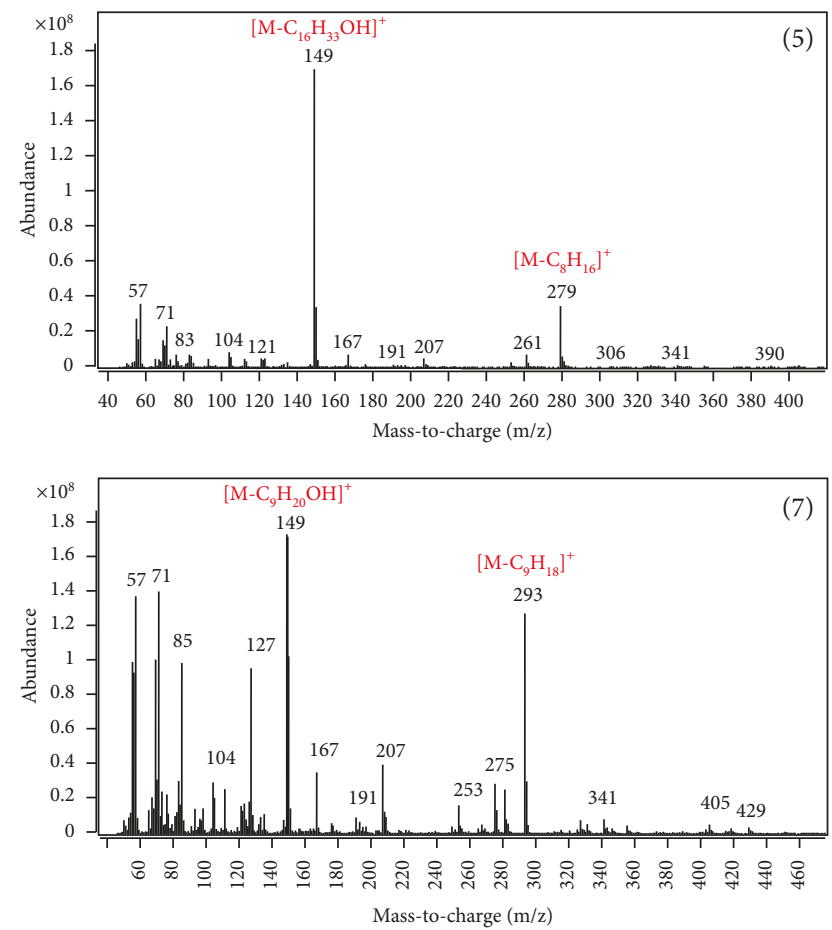

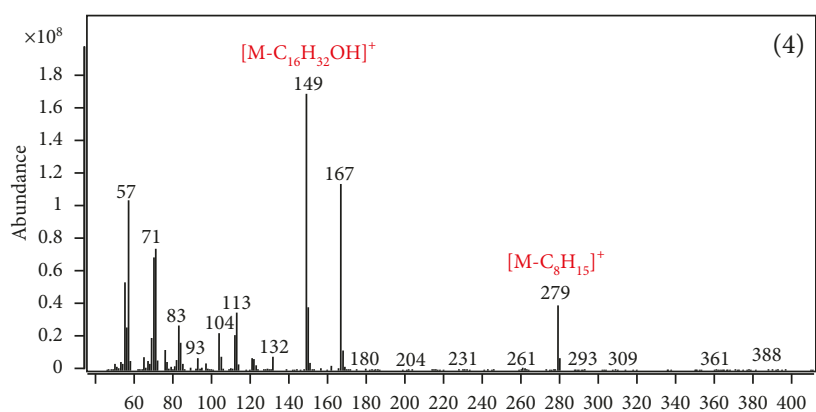

$60 \quad 80100120140160180200220240260280300320340360380400$ Mass-to-charge $(\mathrm{m} / \mathrm{z})$
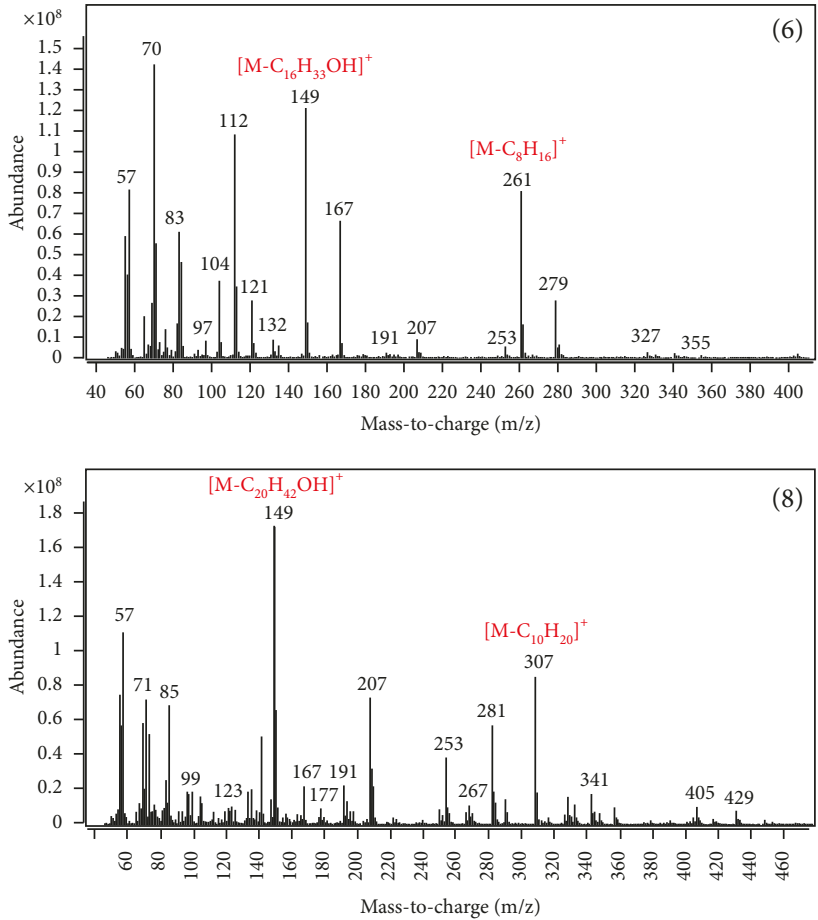

Figure 2: Full-scan MS/MS data of each target analyte to optimized MRM transitions. Each individual parent ion scan experiment is represented as follows: (1) dibutyl phthalate (DBP); (2) benzyl butyl phthalate (BBP); (3) bis(2-ethylhexyl) adipate (DEHA); (4) bis(2ethylhexyl) phthalate (DEHP); (5) di-n-octyl phthalate (DNOP); (6) dioctyl terephthalate (DOTP); (7) diisononyl phthalate (DINP); (8) diisodecyl phthalate (DIDP).

and determined by the analytical procedure. The accuracy and precision were assessed by the average recovery and percentage relative standard deviation (\%RSD) of three results at each concentration, as shown in Table 2. The average recoveries of eight analytes ranged from $91.8 \%$ to $122 \%$, with RSDs ranging from $1.8 \%$ to $17.8 \%$. The linearity, LOQ, accuracy, and precision were summarized in Table 2. The developed method was applied to determine the regulated plasticizers in domestic infusion sets. As detected infusion sets containing DEHP $(5.4 \mu \mathrm{g} / \mathrm{g})$ and DOTP $(153.7 \mu \mathrm{g} / \mathrm{g})$, the chromatogram obtained by the GC-MS SIM mode (a) in comparison with the corresponding chromatogram obtained 
<smiles>CC(C)CCCCCCOC(=O)c1ccccc1C(=O)OCCCCCCC(C)C</smiles>

$\mathrm{m} / \mathrm{z} 418$

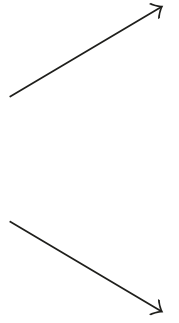

$X_{>}$<smiles>CC(C)CCCCCC[OH+]C(=O)c1ccccc1C(=O)O</smiles>

$\mathrm{m} / \mathrm{z} 293$<smiles>C[NH+]1C(=O)c2ccccc2C1=O</smiles>

$\mathrm{m} / \mathrm{z} 149$

$\mathrm{m} / \mathrm{z} 121$

FIgURE 3: Fragmentation pathway of diisononyl phthalate (DINP) in the MRM mode. A similar fragmentation pattern is found for the other target phthalates. The dominant fragmented ion of $\mathrm{m} / \mathrm{z} 149$ in phthalates is able to distinguish among different alternative plasticizers, such as bis(2-ethylhexyl) adipate (DEHA).

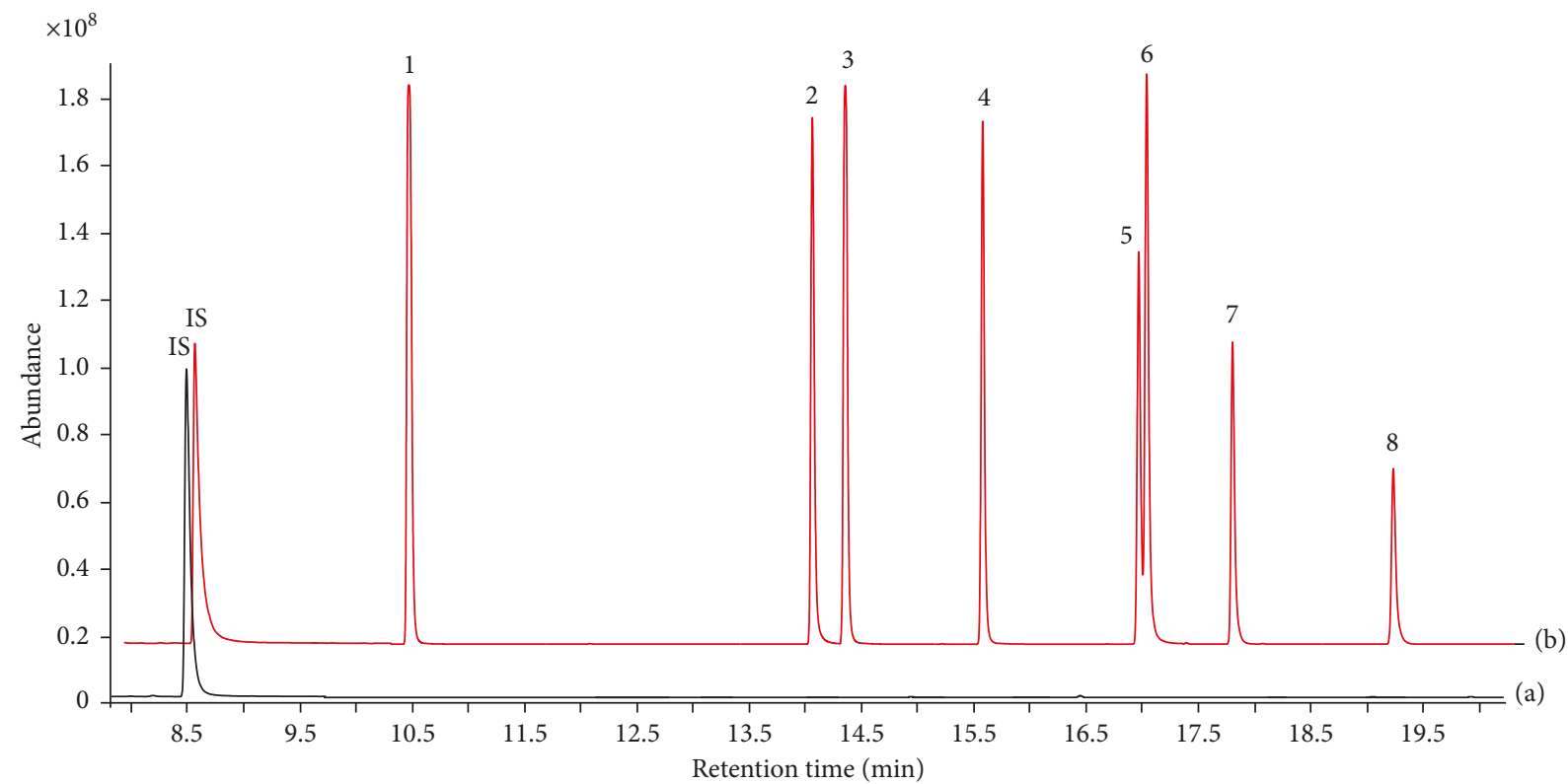

FIGURE 4: GC-MS/MS MRM chromatograms of matrix blank sample (a) and sample spiked with analytes at $5 \mu \mathrm{g} / \mathrm{g}$ (b). Peak identities are as follows: (1) dibutyl phthalate (DBP); (2) benzyl butyl phthalate (BBP); (3) bis(2-ethylhexyl) adipate (DEHA); (4) bis(2-ethylhexyl) phthalate (DEHP); (5) di-n-octyl phthalate (DNOP); (6) dioctyl terephthalate (DOTP); (7) diisononyl phthalate (DINP); (8) diisodecyl phthalate (DIDP); IS, benzyl benzoate (BB).

by the GC-MS/MS MRM mode (b) are shown in Figure 5. Due to the presence of relatively high concentrations of DEHP and DOTP, the calibrations with ten times lower concentration of internal standard, but using the same analyte concentration range, were adopted, and their concentrations in the sample were multiplied by the dilution factor. Upon comparing the chromatograms, the superiority of MRM was obvious. In the MRM mode, the baseline noise of the chromatogram was reduced and distinct peaks appeared, whereas the interferences observed in the SIM mode even look like a false-positive DNOP peak. Apparently, MRM gave higher sensitivity and selectivity than the SIM mode for the determination of target analytes in medical infusion sets.

\section{Conclusion}

The suitability of solvent extraction with the polymer dissolution method followed by the GC-MS/MS MRM mode for the determination of eight regulated plasticizers 
TABLE 2: Linearity, LOQ, accuracy, and precision of target analytes in tubings of medical infusion sets.

\begin{tabular}{|c|c|c|c|c|c|c|}
\hline \multirow{2}{*}{ Compound } & \multirow{2}{*}{$R^{2^{*}}$} & \multirow{2}{*}{ LOQ $(\mathrm{ng} / \mathrm{g})^{\dagger}$} & \multicolumn{2}{|c|}{$17 \mathrm{ng} / \mathrm{g}^{\ddagger}$} & \multicolumn{2}{|c|}{$100 \mathrm{ng} / \mathrm{g}^{\ddagger}$} \\
\hline & & & Accuracy (\%) & Precision (\%RSD) & Accuracy (\%) & Precision (\%RSD) \\
\hline DBP & 0.9996 & 59.5 & 122 & 1.8 & 100 & 11.4 \\
\hline BBP & 0.9996 & 58.6 & 104 & 5.8 & 103 & 13.4 \\
\hline DEHA & 0.9994 & 56.9 & 95.9 & 4.1 & 91.8 & 12.4 \\
\hline DEHP & 0.9991 & 76.3 & 113 & 2.0 & 99.7 & 13.2 \\
\hline DNOP & 0.9993 & 54.1 & 116 & 13.5 & 98.0 & 16.0 \\
\hline DOTP & 0.9997 & 75.5 & 98.8 & 5.4 & 118 & 11.5 \\
\hline DINP & 0.9991 & 72.4 & 121 & 17.8 & 109 & 9.8 \\
\hline DIDP & 0.9994 & 64.1 & 109 & 11.0 & 92.6 & 9.2 \\
\hline
\end{tabular}

*The square of the correlation coefficient; ${ }^{\dagger}$ limit of quantitation (LOQ) refers to the lowest concentrations that can be quantified with adequate accuracy and precision; "the concentrations of the analytes in the spiked samples.

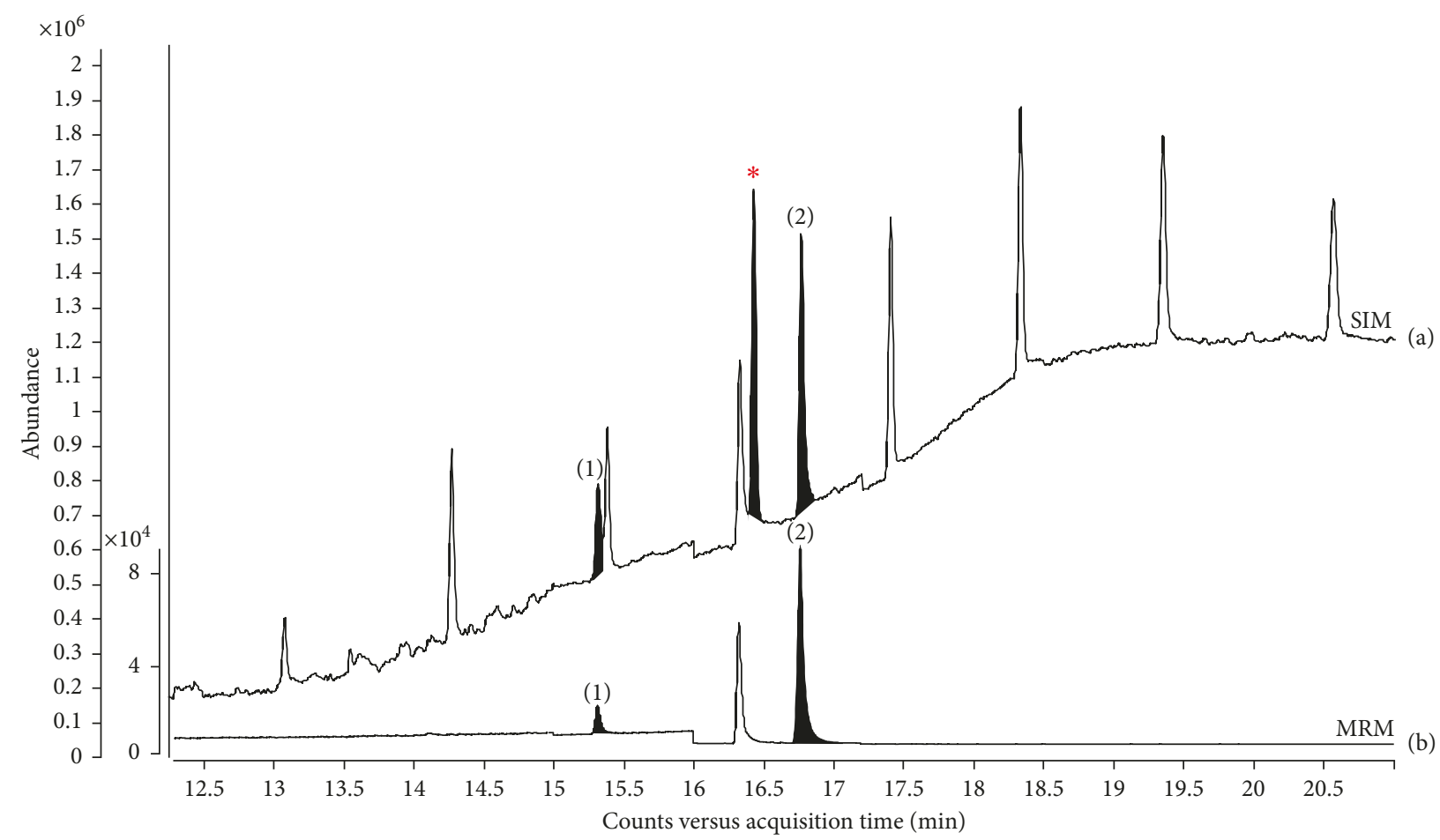

FIGURE 5: GC-MS SIM chromatogram (a) in comparison with the corresponding GC-MS/MS MRM chromatogram (b) in a tubing of medical infusion set containing bis(2-ethylhexyl) phthalate (DEHP) (1) and dioctyl terephthalate (DOTP) (2). SIM chromatogram shows an inconsistent high noise level and interfering peaks, and false-positive identification of di-n-octyl phthalate (DNOP) is represented by an asterisk in SIM chromatogram, but elimination is clear in MRM chromatogram.

(DBP, BBP, DEHA, DEHP, DNOP, DOTP, DINP, and DIDP) in the tubing of medical infusion sets was described. The validated method was successfully used to analyze the samples of medical infusion sets, maintaining high sensitivity and selectivity. The LOQ of this study using the GC-MS/MS MRM mode was lower than those of other studies using conventional GC-MS. The proposed method could be a useful tool to control the safety of intravascular administration sets and to assess unintended harmful substances, especially plasticizers. Furthermore, it will be helpful for biomonitoring as a methodology for tracking the fate of these chemicals associated with human exposures through direct contact and use because the analytical method enables the trace level determination of target analytes.

\section{Conflicts of Interest}

The authors declare that they have no conflicts of interest.

\section{Acknowledgments}

This research was supported by the Bio-synergy Research Project (NRF-2017M3A9C4065961) of the Ministry of Science, ICT, and Future Planning through the National 
Research Foundation and Korea Basic Science Institute grant (C37705).

\section{References}

[1] A. L. Andrady and M. A. Neal, "Applications and societal benefits of plastics," Philosophical Transactions of the Royal Society of London B: Biological Sciences, vol. 364, no. 1526, pp. 1977-1984, 2009.

[2] G. Ginsberg, J. Ginsberg, and B. Foos, "Approaches to children's exposure assessment: case study with diethylhexylphthalate (DEHP)," International Journal of Environmental Research and Public Health, vol. 13, no. 7, p. 670, 2016.

[3] A. Abaamrane, S. Qourzal, M. El Ouardi et al., "Modeling of photocatalytic mineralization of phthalic acid in $\mathrm{TiO}_{2}$ suspension using response surface methodology (RSM)," Desalination and Water Treatment, vol. 53, no. 1, pp. 249-256, 2015.

[4] J. D. Meeker, S. Sathyanarayana, and S. H. Swan, "Phthalates and other additives in plastics: human exposure and associated health outcomes," Philosophical Transactions of the Royal Society of London B: Biological Sciences, vol. 364, no. 1526, pp. 2097-2113, 2009.

[5] P. Mikula, Z. Svobodova, and M. Smutna, "Phthalates: toxicology and food safety-a review," Czech Journal of Food Sciences, vol. 23, no. 6, pp. 217-223, 2005.

[6] J. Adibi, R. Whyatt, D. Camann, K. Peki, W. Jedrychowski, and F. Perera, "Phthalate diester levels in personal air samples during pregnancy in two urban populations," Proceedings of Indoor Air, vol. 4, pp. 177-182, 2002.

[7] B. C. Tran, M. J. Teil, M. Blanchard, F. Alliot, and M. Chevreuil, "Fate of phthalates and BPA in agricultural and non-agricultural soils of the Paris area (France)," Environmental Science and Pollution Research, vol. 22, no. 14, pp. 11118-11126, 2015.

[8] S. E. Serrano, J. Braun, L. Trasande, R. Dills, and S. Sathyanarayana, "Phthalates and diet: a review of the food monitoring and epidemiology data," Environmental Health, vol. 13, no. 1, p. 43, 2014.

[9] M. F. Zaater, Y. R. Tahboub, and A. N. Al Sayyed, "Determination of phthalates in Jordanian bottled water using GC-MS and HPLC-UV: environmental study," Journal of Chromatographic Science, vol. 52, no. 5, pp. 447-452, 2013.

[10] L. Bernard, B. Décaudin, M. Lecoeur et al., "Analytical methods for the determination of DEHP plasticizer alternatives present in medical devices: a review," Talanta, vol. 129, pp. 39-54, 2014.

[11] M. Veiga, D. Bohrer, P. C. Nascimento, A. G. Ramirez, L. M. Carvalho, and R. Binotto, "Migration of phthalate-based plasticizers from PVC and non-PVC containers and medical devices," Journal of the Brazilian Chemical Society, vol. 23, no. 1, pp. 72-77, 2012.

[12] L. Bernard, R. Cueff, C. Breysse, B. Décaudin, V. Sautou, and A. S. Group, "Migrability of PVC plasticizers from medical devices into a simulant of infused solutions," International Journal of Pharmaceutics, vol. 485, no. 1-2, pp. 341-347, 2015.

[13] A. Gomez-Hens and M. P. Aguilar-Caballos, "Social and economic interest in the control of phthalic acid esters," TrAC Trends in Analytical Chemistry, vol. 22, no. 11, pp. 847-857, 2003.

[14] S. H. Swan, K. M. Main, F. Liu et al., "Decrease in anogenital distance among male infants with prenatal phthalate exposure," Environmental Health Perspectives, vol. 113, no. 8, pp. 1056-1061, 2005.
[15] S. Keresztes, E. Tatár, Z. Czégény, G. Záray, and V. G. Mihucz, "Study on the leaching of phthalates from polyethylene terephthalate bottles into mineral water," Science of the Total Environment, vol. 458-460, pp. 451-458, 2013.

[16] H. G. Wahl, A. Hoffmann, H.-U. Häring, and H. M. Liebich, "Identification of plasticizers in medical products by a combined direct thermodesorption-cooled injection system and gas chromatography-mass spectrometry," Jounal of Chromatography A, vol. 847, no. 1-2, pp. 1-7, 1999.

[17] I. S. Kostić, T. D. Anđelković, D. H. Anđelković, T. P. Cvetković, and D. D. Pavlović, "Determination of di(2ethylhexyl) phthalate in plastic medical devices," Hemijska Industrija, vol. 70, no. 2, pp. 159-164, 2016.

[18] L. Bernard, D. Bourdeaux, B. Pereira et al., "Analysis of plasticizers in PVC medical devices: Performance comparison of eight analytical methods," Talanta, vol. 162, pp. 604-611, 2017.

[19] R. Z. Al Bakain, Y. Al-Degs, B. Andri, D. Thiébaut, J. Vial, and I. Rivals, "Supercritical fluid chromatography of drugs: parallel factor analysis for column testing in a wide range of operational conditions," Journal of Analytical Methods in Chemistry, vol. 2017, Article ID 5340601, 13 pages, 2017.

[20] A. P. Tüzüm Demir and S. Ulutan, "Migration of phthalate and non-phthalate plasticizers out of plasticized PVC films into air," Journal of Applied Polymer Science, vol. 128, no. 3, pp. 1948-1961, 2013.

[21] Q. Du, L. Shen, L. Xiu, G. Jerz, and P. Winterhalter, "Di-2ethylhexyl phthalate in the fruits of Benincasa hispida," Food Additives and Contaminants, vol. 23, no. 6, pp. 552-555, 2006.

[22] L. Zhang, C. Shang, and C. Sun, "Simultaneous determination of 17 phthalate esters in Shengmaiyin by gas chromatographytriple quadrupole mass spectrometry," Chinese Journal of Chromatography, vol. 32, no. 6, pp. 653-657, 2014.

[23] T. Niino, T. Asakura, T. Ishibashi et al., "A simple and reproducible testing method for dialkyl phthalate migration from polyvinyl chloride products into saliva simulant," Journal of the Food Hygienic Society of Japan, vol. 44, no. 1, pp. 13-18, 2003.

[24] Q. Wang and B. K. Storm, "Separation and analysis of low molecular weight plasticizers in poly (vinyl chloride) tubes," Polymer Testing, vol. 24, no. 3, pp. 290-300, 2005.

[25] S. Genay, C. Luciani, B. Décaudin et al., "Experimental study on infusion devices containing polyvinyl chloride: to what extent are they di(2-ethylhexyl) phthalate-free?," International Journal of Pharmaceutics, vol. 412, no. 1-2, pp. 47-51, 2011.

[26] P. Gimeno, S. Thomas, C. Bousquet et al., "Identification and quantification of 14 phthalates and 5 non-phthalate plasticizers in PVC medical devices by GC-MS," Journal of Chromatography B, vol. 949-950, pp. 99-108, 2014.

[27] D. Bourdeaux, M. Yessaad, P. Chennell et al., "Analysis of PVC plasticizers in medical devices and infused solutions by GC-MS," Journal of Pharmaceutical and Biomedical Analysis, vol. 118, pp. 206-213, 2016.

[28] S. H. Jeon, J. H. Shin, Y. P. Kim, and Y. G. Ahn, "Determination of volatile alkylpyrazines in microbial samples using gas chromatography-mass spectrometry coupled with head space-solid phase microextraction," Journal of Analytical Science and Technology, vol. 7, no. 1, p. 16, 2016.

[29] J. Möller, E. Strömberg, and S. Karlsson, "Comparison of extraction methods for sampling of low molecular compounds in polymers degraded during recycling," European Polymer Journal, vol. 44, no. 6, pp. 1583-1593, 2008.

[30] K.-C. Ting, M. Gill, and O. Garbin, "GC/MS screening method for phthalate esters in children's toys," Journal of AOAC International, vol. 92, no. 3, pp. 951-958, 2009. 
[31] C. Liao, P. Yang, Z. Xie et al., "Application of GC-triple quadrupole MS in the quantitative confirmation of polycyclic aromatic hydrocarbons and phthalic acid esters in soil," Journal of Chromatographic Science, vol. 48, no. 3, pp. 161-166, 2010.

[32] Z. Guo, S. Wang, D. Wei et al., "Development and application of a method for analysis of phthalates in ham sausages by solid-phase extraction and gas chromatography-mass spectrometry," Meat Science, vol. 84, no. 3, pp. 484-490, 2010.

[33] K. Jaworek and M. Czaplicka, "Determination of phthalates in polymer materials-comparison of GC/MS and GC/ECD methods," Polimeros, vol. 23, no. 6, pp. 718-724, 2013.

[34] X. Meng, X. Zhao, S. Wang et al., "Simultaneous determination of volatile constituents from Acorus tatarinowii schott in rat plasma by gas chromatography-mass spectrometry with selective ion monitoring and application in pharmacokinetic study," Journal of Analytical Methods in Chemistry, vol. 2013, Article ID 949830, 7 pages, 2013.

[35] United States Consumer Product Safety Commission, Test Method: CPSC-CH-C1001-09.3 Standard Operating Procedure for Determination of Phthalates, Consumer Products Safety Commission, Directorate for Laboratory Sciences, Gaithersburg, MD, USA, 2010.

[36] G. T. Deepa, M. Chetti, M. C. Khetagoudar, P. T. Goroji, and D. Bilehal, "Application of GC-MS/MS for pesticide residue analysis in pomegranate fruits," 2010.

[37] Y. A. Jeilani, B. H. Cardelino, and V. M. Ibeanusi, "Density functional theory and mass spectrometry of phthalate fragmentations mechanisms: modeling hyperconjugated carbocation and radical cation complexes with neutral molecules," Journal of the American Society for Mass Spectrometry, vol. 22, no. 11, pp. 1999-2010, 2011.

[38] A. O. Earls, I. P. Axford, and J. H. Braybrook, "Gas chromatography-mass spectrometry determination of the migration of phthalate plasticisers from polyvinyl chloride toys and childcare articles," Journal of Chromatography A, vol. 983, no. 1-2, pp. 237-247, 2003.

[39] ICH Harmonized Tripartite Guideline, Validation of Analytical Procedures: Text and Methodology, Q2(R1), 2005. 

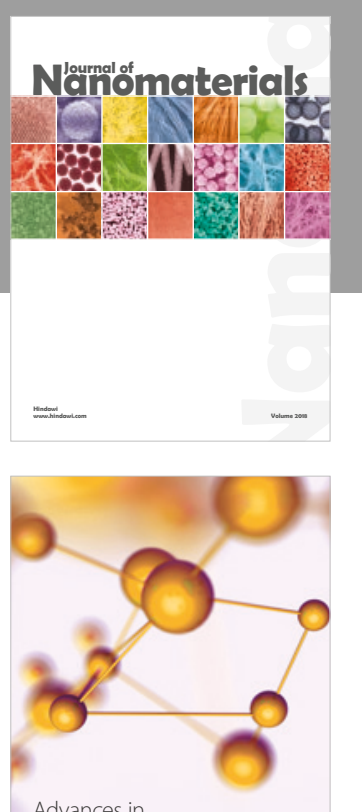

Physical Chemistry
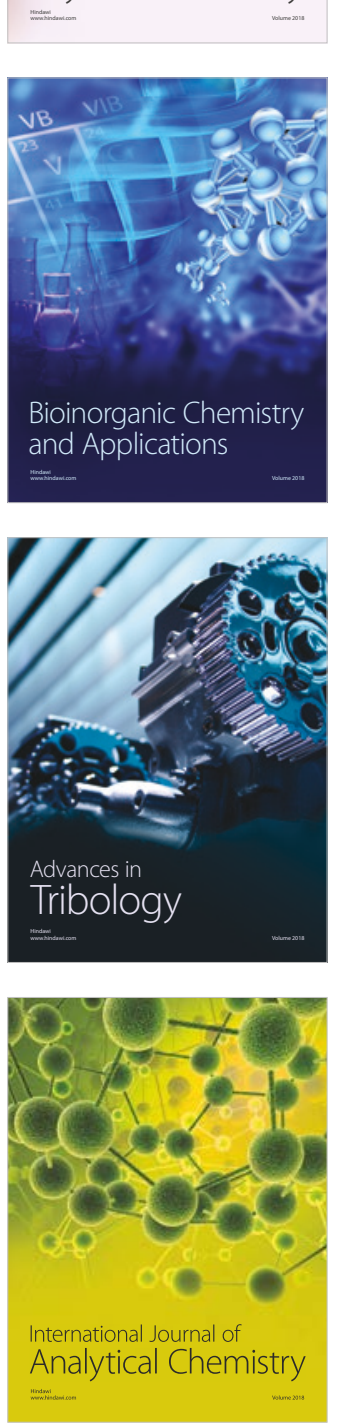

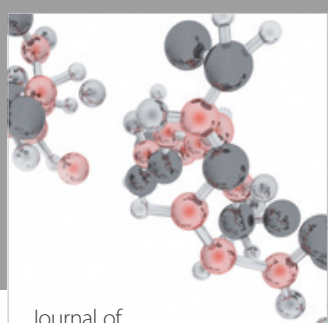

Analytical Methods

in Chemistry

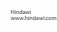

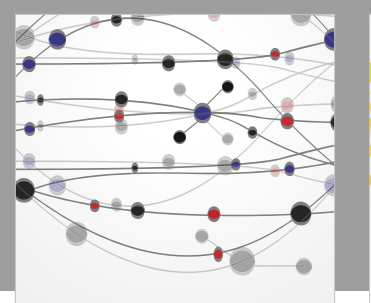

The Scientific World Journal

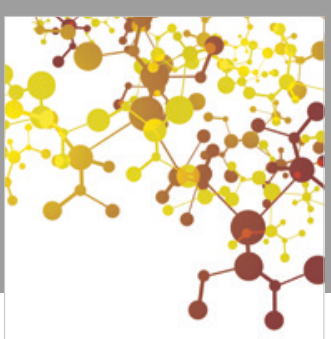

Journal of

Applied Chemistry
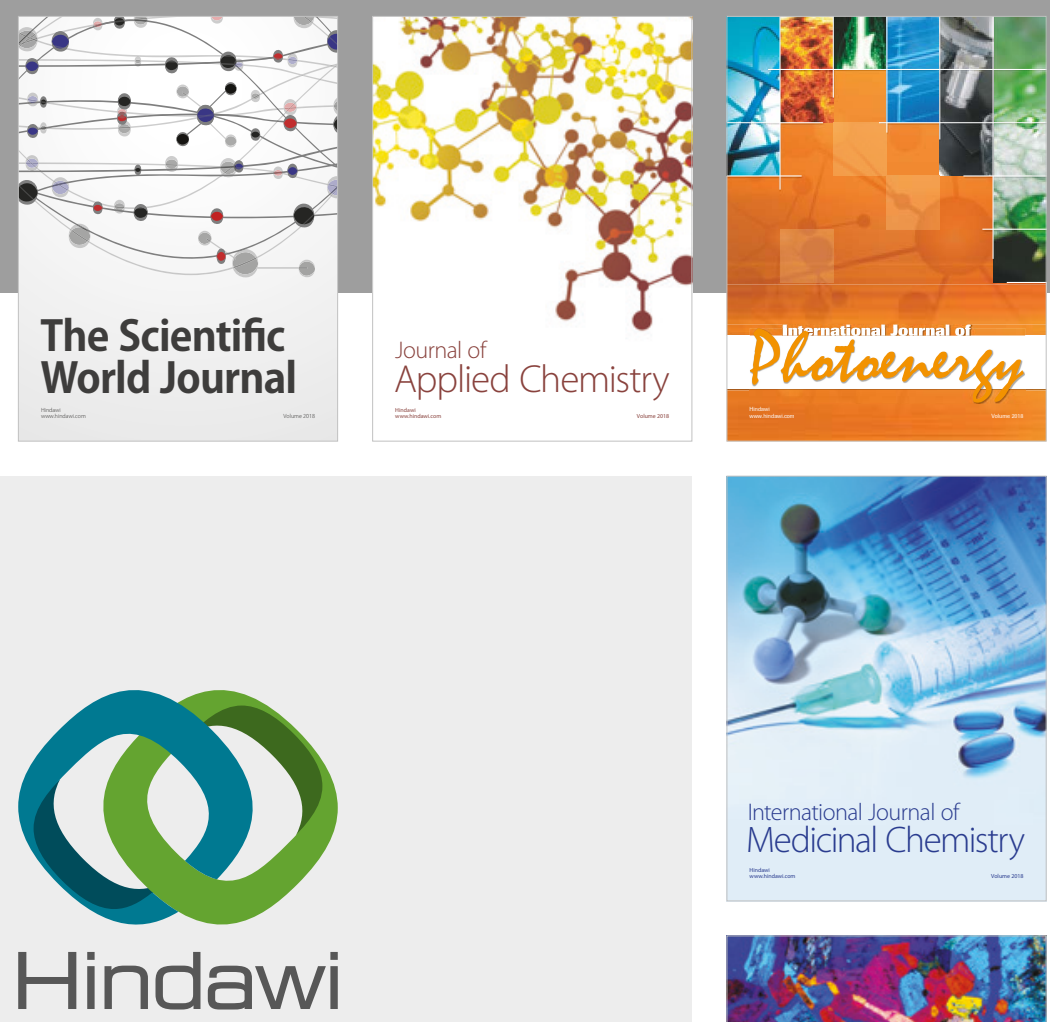

Submit your manuscripts at

www.hindawi.com
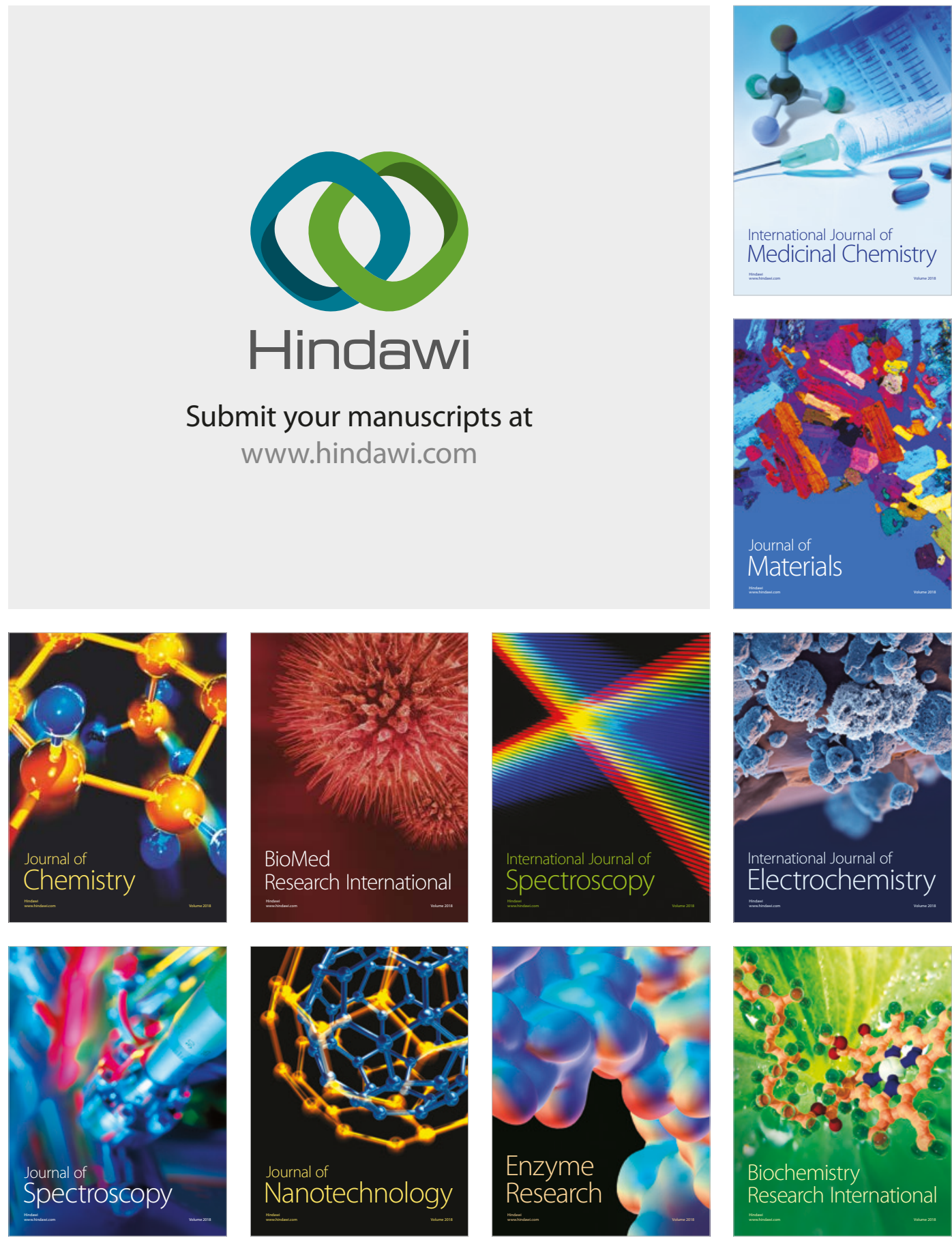
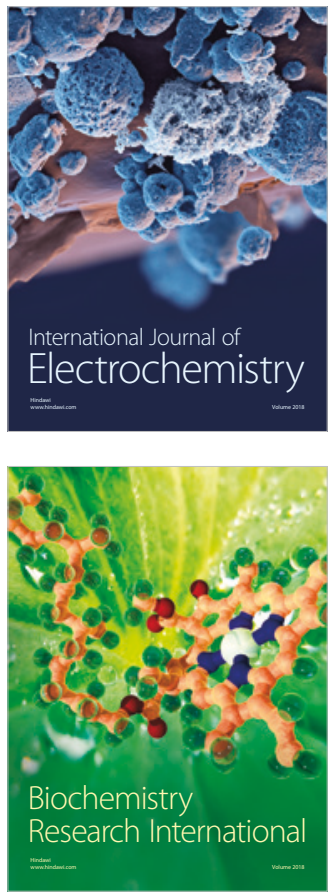